\title{
A Stowaway from Cyprus; Heteropoda venatoria Linnaeus, 1767 (Araneae, Sparassidae)
}

\author{
Kadir Boğaç KUNT'1*, Kemal BASAT1', Recep Sulhi ÖZKÜTÜK² \\ ${ }^{1}$ Cyprus Wildlife Research Institute, Taşkent, Kyrenia, Cyprus \\ ${ }^{2}$ Department of Biology, Faculty of Science, Eskişehir Technical University, TR- 26470 Eskişehir, Turkey \\ ORCID ID: Kadir Boğaç KUNT: https:/ / orcid.org/0000-0003-3137-5510; Kemal BASAT: https:/ /orcid.org/0000-0001-9600-2454; Recep Sulhi \\ ÖZKÜTÜK: https://orcid.org/0000-0001-5030-3008
}

Received: 08.02.2021 Accepted: $11.03 .2021 \quad$ Published online: $31.03 .2021 \quad$ Issue published: 30.06 .2021
Abstract: It is a known phenomenon that the circulation of alien species increases due to many different variables such as the
increase in human commercial activities, the ease of travel between continents, and the decrease in their duration. Pantropical
origin Heteropoda venatoria, due to its synanthropic tendencies, is a spider species that is inclined to travel frequently and to
disperse in the geographies it reaches. In this brief paper, a female Heteropoda venatoria that arrived from Japan to Cyprus via
a merchant ship is presented.

Keywords: Giant crab spider, exotic, spider, alien species.

\section{Kıbrıs'tan Kaçak Bir Yolcu; Heteropoda venatoria Linnaeus, 1767 (Araneae, Sparassidae)}

\begin{abstract}
Öz: Dünya üzerinde insana ait ticarî faaliyetlerin artması, kıtalar arası seyahatlerin kolaylaşıp, sürelerinin azalması gibi birçok farklı değişkene bağlı olarak yabancı türlerin dolaşımlarının arttığı bilinen bir olgudur. Pantropical kökenli Heteropoda venatoria, sinantropik eğilimleri dolayısıyla sık sık seyahate ve ulaştığı coğrafyalarda dağılım göstermeye yatkın bir örümcek türüdür. Bu kısa makalede, Japonya'dan Kıbrıs'a ticarî bir gemi aracılığıyla ulaşan dişi bir Heteropoda venatoria'dan bahsedilmektedir.
\end{abstract}

Anahtar kelimeler: Dev yengeç örümceği, egzotik, örümcek, yabancı tür.

“Dev Yengeç Örümceği” ya da “Muz Örümceği” olarak da isimlendirilen Heteropoda venatoria Linnaeus, 1767, avc1 örümcekleri bünyesinde barındıran Sparassidae familyasına ait bir türdür. Sparassidae üyeleri, Dünya genelinde 87 cinse ait 1262 türle temsil edilmekte olup (WSC, 2021), orta-büyük boylu araneomorf örümceklerdir. Ekribellat, entelijin, sekiz gözlü, laterigrad bacaklı ve çift tarsal tırnaklıdırlar. Ayrıca metatarsuslarının dorsal ucunda üç loblu yumuşak bir zarın varlığı familyanın tanılayıc1 özelliklerindendir (Jocqué \& DippenaarSchoeman, 2007).

Sparassid Örümcekler Kıbrıs'ta beş tür ile temsil edilmektedirler. Bunlar: Eusparassus walckenaeri (Audouin, 1826); Micrommata formosa Pavesi, 1878; M. ligurina (C. L. Koch, 1845); M. virescens (Clerck, 1757) ve Olios suavis (O. Pickard-Cambridge, 1876)'dır (Bosmans et al., 2019). Bunların tamamı Akdeniz havzası ve çevresinde görülmesi olanaklı, yerli türlerdir.

Doğal dağılım alanı Tropikal Asya olan Heteropoda venatoria zaman içinde insan faaliyetlerine bağlı olarak, özellikle ticarî muz taşımacılığı sebebiyle, Pasifik Adaları, Yeni Dünya (Kuzey, Orta ve Güney Amerika), Makaronezya, Avrupa ve Afrika'ya da giriş yapmıştır (WSC, 2021).

Heteropoda venatoria, saldırgan değil tam tersine ürkek bir örümcek türüdür. Rahatsız edilmesi halinde son derece hızlı hareket eder. İri cüssesine rağmen yassı vücudu ve esnek bacakları sayesinde küçük çatlaklara giriş çıkış yapabilme kabiliyetine sahiptir. Günümüzde muz tarımında, muzu zararlı böceklere karşı korumak için biyolojik mücadele ajanı olarak kullanılmaktadır. İnsanla teması durumunda nadiren isırılma vakası görülse de, $H$. venatoria'nın zehrinin tıbbî önemi yoktur. Isırılan bölgede geçici ağrı ve şişlik bilinen semptomlardandır (Ewunkem et al., 2016).

Olay: 04.12.2020 günü Kıbrıs, Girne, Taşkent'te faaliyet gösteren kâr amacı gütmeyen özel bir kuruluş olan "Kıbrıs Yaban Hayat Araştırma Enstitüsü" arandı. Telefondaki kişi “yaklaşık 45 gün evvel Japonya'nın Osaka Limanından ayrilan bir yük gemisinden indirilen konteynerde büyük bir örümceğin varlığından" bahsediyordu. Bunun üzerine kişi ile temasa geçen Kıbrıs Yaban Hayat Araştırma Enstitüsü görevlisi, örümceği enstitüye bağlı Yaban Hayat Kurtarma ve Rehabilitasyon Merkezine iletmek üzere tutanak karşılığında teslim aldı. Tutanakta örümceğin durumu kritik (24 saat içerisinde ölebilir) olarak işaretlenmiştir. Nitekim örümcek merkeze naklinin hemen ardından yüksek olasılıkla susuzluk, ağır stres ve üşüme gibi nedenlerden dolayı ölmüştür. Bunun ardından etil alkole konulan örnek, enstitü uzmanlarınca, Jäger (2000)'e göre, Heteropoda venatoria (dişi birey) olarak teşhis edilip koruma altına alınmıştır (Şekil 1).

Heteropoda venatoria'nın ticarî gemiler aracılığıyla seyahat edip, ulaştıkları coğrafyalarda yaşama imkânı bulmaları daha önceleri çeşitli yazarlar tarafından bildirilen bir olgudur. Örneğin, Taucare-Ríos \& Brescovit 
(2011)'in Şili kayıtları bunlardan sadece biridir. Bizim kaydımızın ada faunası açısından sevindirici tarafı; örneğin tek, sağlıksız ve doğaya kavuşamadan alıkonulmuş olmasıdır.
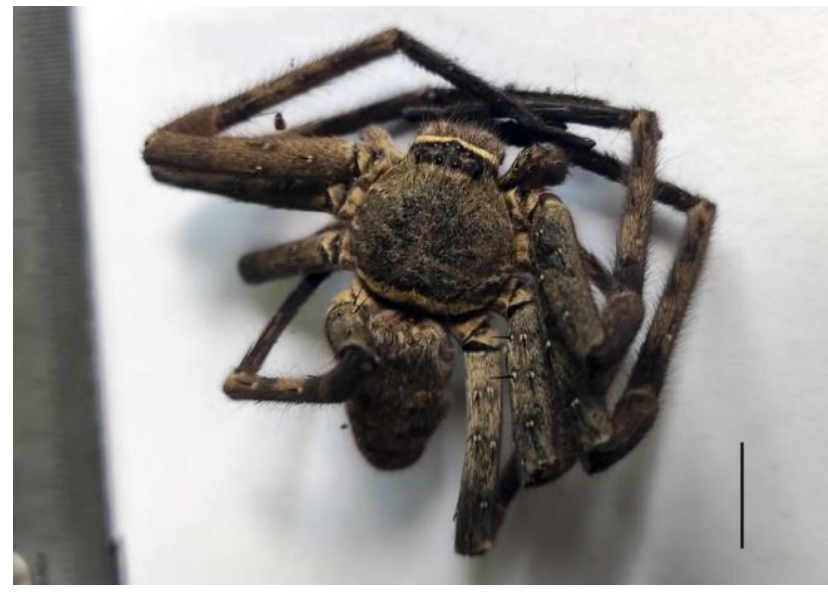

Şekil 1. Heteropoda venatoria, ölüm sonrası fotoğraf. Ölçek çizgisi: $10 \mathrm{~mm}$

Kıbrıs'ın yoğun ticarî ve turistik trafiği adaya yabancı türlerin girişini kolaylaştırmaktadır. Örneğin bir yaprak zararlisı olan Chrysolina (Chrysolinopsis) americana (Linnaeus, 1758) (Coleoptera, Chrysomelidae) türü bu makalenin değerlendirilme sürecinde Kıbrıs'tan rapor edilmiştir (Hadjiconstantis \& Zoumides, 2021). Yine bir başka Örümceğimsi türü olan Euscorpius italicus (Herbst, 1800) (Scorpiones: Euscorpiidae)'nin de adadaki varlığ muhtemelen taşınmaya bağlıdır (Yağmur, 2012). Bununla birlikte, mevcut literatüre göre Kıbrıs'ta dağılım gösteren örümceklerin tamamı yerli türler olup içlerinde yabancı tür bulunmamaktadır (Bosmans et al., 2019). Ancak ada olması sebebi, ulaşım ve taşıma yoğunluğu dolayısıyla yabancı türlerin Kıbrıs'a giriş olasılığı her zaman mümkün olup doğası açısından potansiyel bir tehlike arz etmektedir. Bunun önüne geçebilmek adına adaya giren ticarî mallara yönelik kontrollerin yoğunlaştırılması, gümrük memurlarına ve özellikle giriş bölgelerinin yakınlarında yaşayan halka yönelik eğitim çalışmaları akla ilk gelen önlemler arasında sıralanabilir.

Teşekkür: Örümcek örneğinin enstitüye intikalini sağlayan, fotoğraflarını çeken Mustafa Güray Bukan'a teşekkür ederiz.

Etik kurul onayı: Bu çalışma için etik kurul onayı alınmasına gerek yoktur.

Çıkar çatışması: Yazarlar, çıkar çatışması olmadığını beyan etmiştir.

\section{Kaynaklar}

Bosmans, R., Keer, J. V., Russell, A., Hadjiconstantis, M., Komnenov, M., Bosselaers, J., Huber, S., Mccowan, D., Snazell, R., Decae, A., Zoumides, C., Kielhorn, K.-H., \& Oger, P. (2019). Spiders of Cyprus (Araneae): A catalogue of all currently known species from Cyprus. Newsletter Belgian Arachnological Society, 34, 1-173.

Ewunkem, J. A., Ntonifor, N. N., \& Parr, M. C. (2016). Bioecology of Heteropoda venatoria (Linnaeus) (Araneae: Sparassidae) and its implications in a tropical banana agroecosystem. Journal of Global Agriculture and Ecology, 5(3), 164-175.

Hadjiconstantis, M., \& Zoumides, C. (2021). First records of the pest leaf beetle Chrysolina (Chrysolinopsis) americana (Linnaeus, 1758) (Coleoptera, Chrysomelidae) in Cyprus - A study initiated from social media. Biodiversity Data Journal, 9, e61349. https:// doi.org/10.3897/BDJ.9.e61349
Jäger, P. (2000). Selten nachgewiesene Spinnenarten aus Deutschland (Arachnida: Araneae). Arachnologische Mitteilungen, 19, 49-57. https://doi.org/10.5431/aramit1907

Jocqué, R., \& Dippenaar-Schoeman, A. S. (2007). Spider families of the world (2nd ed). Musée royal de l'Afrique centrale; ARC-PPRI.

Taucare-Ríos, A., \& Brescovit, A. D. (2011). La araña cangrejo gigante Heteropoda venatoria (Linnaeus, 1767) (Araneae: Sparassidae: Heteropodinae) en Chile. Boletín de Biodiversidad de Chile, 5, 39-44.

World Spider Catalog (2021). Natural History Museum Bern. Retrieved from http://wsc.nmbe.ch. https://doi.org/10.24436/2

Yağmur, E. A. (2012). First Record of the Genus Euscorpius Thorell, 1876 (Scorpiones: Euscorpiidae) in Cyprus. Acta Zoologica Bulgarica, 64(3), 329-330. 